\title{
Splenic infarction after laparoscopic sleeve gastrectomy
}

\author{
(1) İsmail Ertuğrul, ${ }^{1}$ (1) Faik Yaylak, ${ }^{2}$ (1) Merve Şenkul, ${ }^{1}$ (1) Eray Atlı, ${ }^{3}$ (1) Ali Tardu ${ }^{4}$ \\ 'Department of Gastrointestinal Surgery, Evliya Çelebi Training and Research Hospital, Kütahya, Turkey \\ 2Department of General Surgery, Dumlupınar University Faculty of Medicine, Kütahya, Turkey \\ ${ }^{3}$ Department of Radiology, Okan University Faculty of Medicine, İstanbul, Turkey \\ ${ }^{4}$ Department of Gastrointestinal Surgery, Sultan Murat-I Public Hospital, Edirne, Turkey
}

\begin{abstract}
Laparoscopic sleeve gastrectomy is a common procedure for obesity with well-defined complications. This case report describes a splenic infarction observed after a laparoscopic sleeve gastrectomy performed in a 32 -year-old female patient with a body mass index of $41 \mathrm{~kg} / \mathrm{m}^{2}$. On the postoperative second day she presented with left-sided thoracic pain and fever. Intravenous contrast-enhanced computed tomography (CT) revealed a splenic infarction in the upper pole. The patient was treated conservatively with antibiotics and analgesics. She was discharged on the postoperative sixth day. One month later, patient was symptom-free at the control visit. A follow-up CT demonstrated regression on the infarction side with minimal residue. Splenic infarction after laparoscopic sleeve gastrectomy is a rare, early surgical complication. Diagnosis is made with confirmation of clinical signs using CT. Conservative treatment is adequate for most patients. In our case, a retrospective review of the laparoscopic images revealed the ischemic areas after the division of the short gastric vasculature.
\end{abstract}

Keywords: Laparoscopic sleeve gastrectomy; morbid obesity; splenic infarction.

\section{Introduction}

Laparoscopic sleeve gastrectomy (LSG) is a common surgical procedure for the treatment of morbid obesity. [1] LSG restricts the gastric volume and decreased fundal Ghrelin levels result with diminished oral intake and appetite. ${ }^{[2]}$ Surgical complications of LSG are well defined. These complications include bleeding, leakage, stenosis, intraabdominal abcess, delayed gastric emptying or gastric dilatation. Rarely splenic complications have been reported..$^{[3,4]}$

In this report a splenic infarction after (LSG) has been presented.

\section{Case Report}

32 years old female with BMI 41 was scheduled for LSG. On postoperative day two she was presented with left thoracic pain and fever. Otherwise vital signs were stable and laboratory tests were in normal range. Pulmonary emboli was excluded with computed tomography (CT) angiography. However, splenic infarction was observed in the upper splenic pole. Diagnosis was confirmed with iv enhanced abdominal CT (Fig. 1a). Patient was treated conservatively. She was discharged on postoperative day six. One month after surgery CT control has demonstrated regression of infarct area (Fig. 1b). 

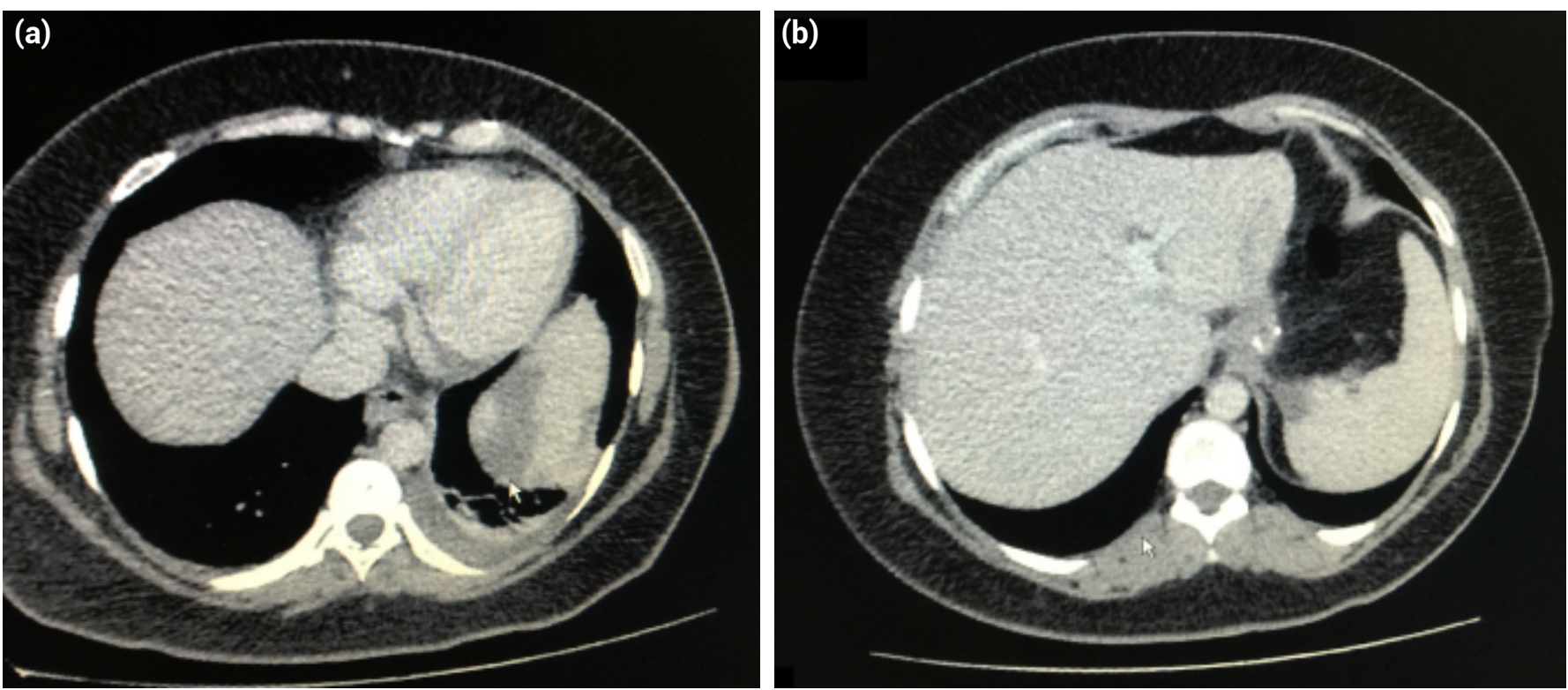

Figure 1. (a) Infarct sides in the upper splenic pole, iv contrast enhanced CT. (b) Regression of infarction area one months after conservative treatment, iv contrast enhanced CT.

\section{Discussion}

LSG was introduced as a bridge treatment for the surgical treatment of super obesity. ${ }^{[5]}$ Then it was recognized for the short and long term excess weight reduction and is now a common procedure for treatment of obesity.

Splenic infarction and splenic abcess formation has been reported after laparoscopic Nissen fundoplication due to division of short gastric vasculature. ${ }^{[6-8]}$ LSG requires gastric fundus mobilization and division of short gastric vasculature. Thus, upper pole ischemia and necrosis may be observed. Previous reports have documented splenic infarcts in the early postoperative course. Some cases may be more complicated with splenic abscess development. $\mathrm{CT}$ is essential in the diagnosis of early complications after LSG. ${ }^{[9-11]}$ Bleeding and early leakage may be life threatening complications to be excluded. In our case splenic infarction was observed with CT angiography review of the laparoscopic images has revealed the ischemic areas after division of short gastric vasculature.

Isolated splenic infarcts are commonly treated conservatively. Abscess is drained under USG guidance or with laparoscopy. ${ }^{[12]}$ Multiple splenic abscess may rarely require splenectomy for those patients with multiple splenic abcess. ${ }^{[12,13]}$ Abscess formation was not observed and in control CT infarct area was regressed.

\section{Conclusion}

Splenic infarction should be remembered in those pa- tients with pain and fever after LSG. Close intraoperative observation during after short gastric vasculature may demonstrate early signs of splenic upper pole infarction. Usually the first approach should be conservative.

\section{Disclosures}

Informed Consent: Written informed consent was obtained from the patient for the publication of the case report and the accompanying images.

Peer-review: Externally peer-reviewed.

Conflict of Interest: None declared.

\section{References}

1. Sherman V, Brethaer SA, Chand B, Schauer. Laparoscopic sleeve gastrectomy. In: Schauer PR, Schirmer BD, Brethauer SA, editors. Minimally invasive bariatric surgery. New York: Springer Inc; 2007. p. 173-8. [CrossRef]

2. Serra C, Pérez N, Bou R, Bengochea $M$, Martínez R, Baltasar A. Laparoscopic sleeve gastrectomy. A bariatric procedure with multiple indications [Article in Spanish]. Cir Esp 2006;79:289-92. [CrossRef]

3. Nores M, Phillips EH, Morgenstern L, Hiatt JR. The clinical spectrum of splenic infarction. Am Surg 1998;64:182-8.

4. Antopolsky M, Hiller N, Salameh S, Goldshtein B, Stalnikowicz R. Splenic infarction: 10 years of experience. Am J Emerg Med 2009; 27:262-5. [CrossRef]

5. Ren CJ, Patterson E, Gagner M. Early results of laparoscopic biliopancreatic diversion with duodenal switch: a case series of 40 consecutive patients. Obes Surg 2000;10:514-23.

6. Martínez DG, Sánchez AW, García AP. Splenic abscess after 
laparoscopic Nissen fundoplication: a consequence of short gastric vessel division. Surg Laparosc Endosc Percutan Tech 2008;18:82-5. [CrossRef]

7. Wilkinson NW, Edwards K, Adams ED. Splenic infarction following laparoscopic Nissen fundoplication: management strategies. JSLS 2003;7:359-65.

8. Ipek T, Eyuboglu E, Ozben V. Partial splenic infarction as a complication of laparoscopic floppy Nissen fundoplication. J Laparoendosc Adv Surg Tech A 2010;20:333-7. [CrossRef]

9. Singh YS, Cawich S, Aziz I, Naraynsingh V. Delayed splenic abscess after laparoscopic sleeve gastrectomy. BMJ Case Rep 2015. [CrossRef]
10. Avulov V, McQuillen DP, Mizusawa M, Brams D. Splenic abscess after sleeve gastrectomy. SAGES Metab Obes Arch 2014;7:71.

11. Sakran N, Iliviitzki A, Zeina AR, Assalia A. Splenic abscess after sleeve gastrectomy: a report of two cases. Obes Facts 2012;5:635-9. [CrossRef]

12. Carbonell $A M$, Kercher KW, Matthews BD, Joels CS, Sing RF, Heniford BT. Laparoscopic splenectomy for splenic abscess. Surg Laparosc Endosc Percutan Tech 2004;14:289-91.

13. Kassir R, Debs T, Ben Amor I, Tiffet $O$, Blanc $P$, Caldwell J, et al. Management of complications following bariatric surgery: summary. Int. J Surg 2014;12:1462-4. [CrossRef] 